\title{
The Interaction of Histamine with Gastrin and Carbamylcholine on Oxygen Uptake by Isolated Mammalian Parietal Cells
}

\author{
ANDREw H. Soll, Veterans Administration Wadsworth Hospital Center, Los Angeles, \\ California 90073, and the University of California at Los Angeles School of \\ Medicine, Los Angeles, California 90024
}

A B S T R A C T Using oxygen uptake as an index of the physiological response of isolated parietal cells, the interactions between histamine and gastrin and between histamine and carbamylcholine and the effects of atropine and metiamide on these interactions have been studied. Parietal cells were isolated from canine fundic mucosa by sequential exposure of separated mucosa to collagenase and EDTA. In previous studies carbamylcholine, isobutyl methyl xanthine, gastrin, and histamine have each been shown to increase oxygen uptake by these cells. Isobutyl methyl xanthine greatly enhanced the histamine effect. Carbamylcholine was inhibited by atropine but not by metiamide, histamine was inhibited by metiamide but not by atropine, and gastrin was inhibited by neither, suggesting that each of these agents has a direct action on the parietal cell. In the present studies, potentiating interactions between histamine and carbamylcholine and between histamine and gastrin have been demonstrated. Against a histamine $(0.1$ and $1 \mu \mathrm{M})$ plus isobutyl methyl xanthine $(0.1 \mathrm{mM})$ background, the dose for $50 \%$ response for gastrin was approximately 1 $\mathrm{nM}$, and the maximal response was obtained at $0.1 \mu \mathrm{M}$. When added to these combinations of stimulants, metiamide and atropine retained their respective specificities against stimulation by histamine and carbamylcholine, in that responses were inhibited to the level that was seen when the component of the pair that was not inhibited was given alone.

The observation that histamine plus gastrin and

This work was presented, in part, at the meeting of the American Gastroenterological Association, 22 to 27 May 1976, Miami, Fla. (1) and the First International Symposium on Gastrointestinal Hormones, 5 to 8 October 1976, Asilomar, Calif. (2).

Dr. Soll is the recipient of a Research Associateship from the Veterans Administration.

Received for publication 7 June 1977 and in revised form 22 September 1977. histamine plus carbamylcholine produced maximal responses that were greater than the maximal response to histamine alone further supports the hypothesis that these agents each have direct actions on parietal cells. These observations are not consistent with the hypothesis that histamine is the sole mediator for the effects of other secretagogues. Furthermore, the inhibitory effects of atropine and metiamide on the specific cholinergic and histaminic components of the interactions that occur between secretagogues provide a possible explanation for the apparent lack of specificity of these agents on in vivo acid secretion.

\section{INTRODUCTION}

Histamine, gastrin, and cholinergic agents each stimulated oxygen consumption by dispersed parietal cells prepared from canine fundic mucosa (3). Parietal cells appeared to largely account for these increases in oxygen consumption. Based upon the correlation of acid secretion and oxygen consumption in in vitro studies with amphibian mucosa and with an ex vivo stomach preparation (3), the increases in oxygen consumption by the isolated parietal cells were taken as evidence of stimulation of the parietal cell acid secretory mechanisms. In this previous study, data was obtained suggesting that the parietal cells have separate receptors for each of these agents, since histamine was inhibited by metiamide but not by atropine, carbamylcholine was inhibited by atropine but not by metiamide, and gastrin was inhibited by neither atropine nor metiamide (3). These results, however, are in apparent conflict with in vivo studies of acid secretion in which atropine inhibits the actions of histamine (4-6) and gastrin $(5,7)$, as well as acetylcholine, and in which $\mathrm{H}_{2}$-histamine antagonists inhibit the actions of gastrin (8-12) and cholinergic agents $(13,14)$, as well as histamine. This apparent nonspecificity of 
inhibitors may be the result of the sequential action of secretagogues with, for example, gastrin releasing mucosal histamine and histamine in turn acting directly upon the parietal cell. $\mathrm{H}_{2}$-blockers would then interfere with the histamine mediation of gastrin action. A second possibility is that the $\mathrm{H}_{2}$-antagonists and anticholinergic agents may block receptors other than for histamine and acetylcholine, respectively, thus interfering with the receptor binding of presumably unrelated agents. Alternatively, endogenous mucosal histamine and (or) acetylcholine may be released spontaneously in the basal state and may interact with other secretagogues on the parietal cell. The apparent lack of specificity of $\mathrm{H}_{2}$-antagonists and anticholinergics would then reflect specific inhibition of the histaminic and cholinergic components of these interactions. In the present study, with oxygen uptake as an index of the physiological response of dispersed parietal cells, the interactions between histamine and gastrin and between histamine and cholinergic agents, and the effects of atropine and metiamide on these interactions, were examined.

The findings of these studies are compatible with a model based upon interaction of secretagogues at the parietal cell in which the inhibitory actions of anticholinergics and $\mathbf{H}_{2}$-receptor antagonists against combinations of stimulants can be explained by their respective removal of the cholinergic and histaminic components of these interactions.

\section{METHODS}

Cells were prepared from canine fundic mucosa which was completely separated from submucosa and then incubated in basal essential medium with crude collagenase III (Worthington Biochemical Corp., Freehold, N.J., $0.75 \mathrm{mg} / \mathrm{ml}$ ), followed by incubation in the same medium with $1-2 \mathrm{mM}$ EDTA, and then returned to the collagenase containing medium. These methods and the methods for determining oxygen uptake and for data analysis have been detailed previously (3). The present studies were done both on crude mucosal cell fractions and on enriched parietal cell fractions obtained with the Beckman elutriator rotor (Beckman Instruments, Inc., Fullerton, Calif.) (3).

The data are expressed as the percentage of the maximal increment above basal produced by $10 \mu \mathrm{M}$ histamine plus $0.1 \mathrm{mM}$ isobutyl methyl xanthine, the only exception being the dose-response studies with gastrin, where the data are expressed as the percentage of the maximal increment above the histamine plus isobutyl methyl xanthine (IMX) ${ }^{1}$ background produced by $0.1 \mu \mathrm{M}$ gastrin and Table I where the data are expressed as the percentage increase over basal oxygen uptake. These transformations to the percentage of a maximal increment above basal or background greatly facilitate combining data from different experiments (3). The percentage increases in oxygen uptake for each preparation are noted in the figure legends, and the absolute rates of oxygen consumption can be calculated from these data and from the

\footnotetext{
${ }^{1}$ Abbreviations used in this paper: $\mathrm{D}_{50}$, dose for $50 \%$ response; IMX, isobutyl methyl xanthine.
}

mean basal oxygen uptake for crude and enriched cell fractions (3).

In previous studies (3), the phosphodiesterase inhibitor IMX was found to markedly enhance the response to histamine, and in the present studies this agent was included at $0.1 \mathrm{mM}$ in all incubations in which histamine was used unless otherwise noted.

\section{RESULTS}

Histamine-gastrin interactions. Gastrin (natural hog heptadecapeptide gastrin, $0.1 \mu \mathrm{M}$ ) which alone produced a $12 \%$ increase in oxygen uptake above basal (3), markedly enhanced the response to histamine. This combination of $0.1 \mu \mathrm{M}$ gastrin with $10 \mu \mathrm{M}$ histamine produced a response in nine consecutive preparations that was $157 \pm 8.2 \%$ (mean $\pm \mathrm{SE}$ ) of the maximal increment above basal produced by histamine, with a range from 114.7 to $191.5 \%$ and the difference statistically significant by the $t$ test for paired values $(P<0.01)$. In each of these nine preparations the response to the combination of histamine plus gastrin was greater than the sum of the responses to the individual agents, and this difference was statistically significant by the paired $t$ test $(P<0.01)$. In four preparations, the effect of $0.1 \mu \mathrm{M}$ gastrin upon the dose-response relation to histamine was studied, and enhancement by gastrin was evident at histamine concentrations from $0.1 \mu \mathrm{M}$ to $0.1 \mathrm{mM}$ (Fig. 1). This

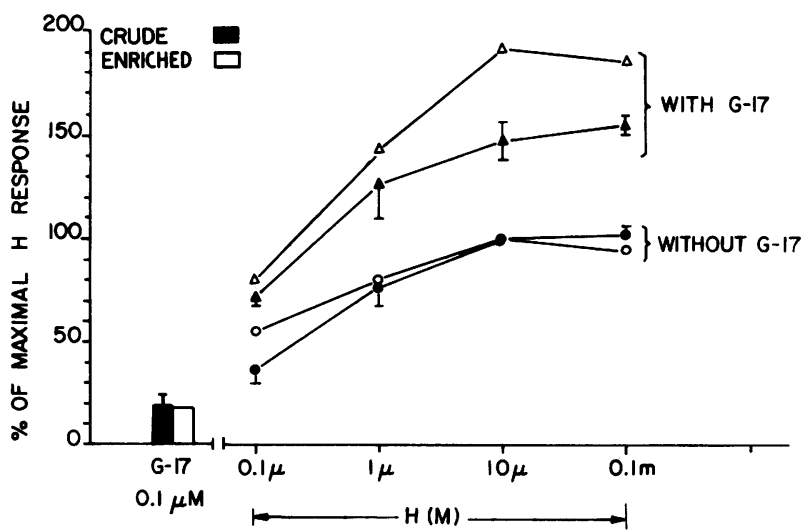

FIgurE 1 The effect of gastrin on the dose-response relationship for histamine $(\mathbf{H})$. Oxygen uptake is expressed as the percentage of the maximal increment above basal produced by $10 \mu \mathrm{M}$ histamine. The responses to histamine (๑), histamine plus $0.1 \mu \mathrm{M}$ heptadecapeptide gastrin (G-17) $(\Delta)$, and $0.1 \mu \mathrm{M} \mathrm{G}-17$ alone (closed bar) were studied in three separate preparations of unenriched cells and in a single enriched preparation with $53 \%$ parietal cells (histamine, $\mathrm{O}$; histamine plus $0.1 \mu \mathrm{M} \mathrm{G}-17, \Delta$; and $0.1 \mu \mathrm{M} \mathrm{G}-17$ alone, open bar). In the separate preparations each point represents at least duplicate independent determinations. Error bars represent $\mathrm{SE}$, based upon preparation means. $10 \mu \mathrm{M}$ histamine produced a mean response of $89.7 \pm 7.6 \%$ above basal in the preparations of unenriched cells and $42.3 \%$ above basal with the enriched cells. $0.1 \mathrm{mM}$ IMX was present when histamine was used. 
enhancement by gastrin of the action of histamine was qualitatively similar in the unenriched and enriched parietal cell fractions.

The enhancement by histamine of gastrin-stimulated oxygen uptake facilitated the study of the doseresponse relation of gastrin. The gastrin dose-response relation was studied against a background of 0.1 and $1 \mu \mathrm{M}$ histamine (Fig. 2). To allow the data in the three separate preparations to be combined, the data are expressed as the percentage of the maximal increment of gastrin-stimulated oxygen uptake above the histamine background. The maximal response to gastrin was observed at $0.1 \mu \mathrm{M}$ in two of the three preparations, with the dose for $50 \%$ response $\left(D_{50}\right)$ estimated at $1 \mathrm{nM}$.

For all of the above experiments, $0.1 \mathrm{mM}$ IMX was present whenever histamine was studied. Histaminegastrin interactions in the absence of IMX have been examined on three occasions and although the combination produced a response that was greater than the responses to either agent alone, the differences were small and not statistically significant with the number of observations obtained (data not shown).

Effects of metiamide and atropine on the histamine-gastrin interaction. The effect of $10 \mu \mathrm{M}$ metiamide on the histamine-gastrin interaction was

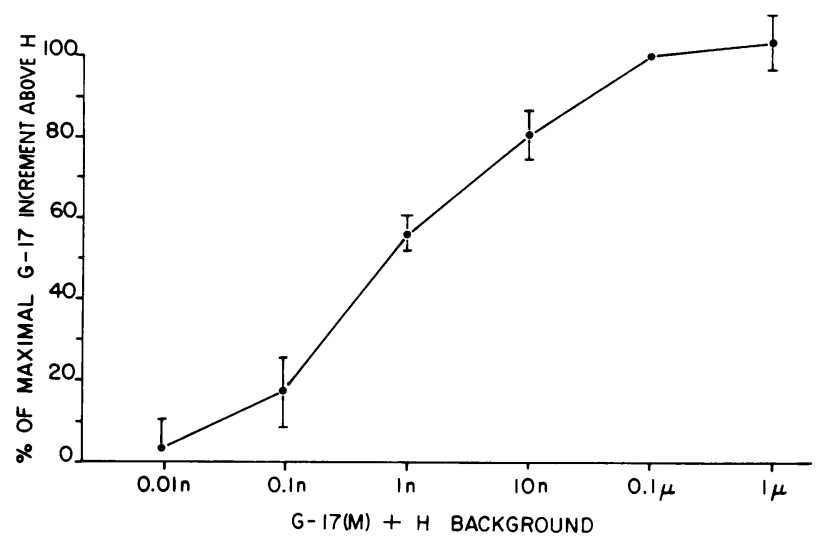

Figure 2 The dose-response relationship to gastrin with a histamine $(\mathrm{H})$ background. The dose-response relationship for heptadecapeptide gastrin (G-17) was tested with a histamine background of $1 \mu \mathrm{M}$ in one preparation and $0.1 \mu \mathrm{M}$ in two others. The data represent the mean $\pm S E$ (based upon preparation means) for at least duplicate determinations in each preparation and have been expressed as the percentage of the maximal increment above the histamine background produced by the addition of $0.1 \mu \mathrm{M}$ G-17. This concentration of gastrin produced a maximal response in two of the three preparations. In these experiments $0.1 \mu \mathrm{M}$ histamine produced responses 14.0 and $17.6 \%$ above basal. The addition of G-17 $(0.1 \mu \mathrm{M})$ produced responses that were, respectively, 57.8 and $46.4 \%$ above basal. The $1 \mu \mathrm{M}$ histamine background produced a response that was $38.2 \%$ above basal and the addition of $0.1 \mu \mathrm{M} \mathrm{G}-17$ resulted in a response $92.3 \%$ above basal. $0.1 \mathrm{mM}$ IMX was present for all incubations with histamine. studied with gastrin at $0.1 \mu \mathrm{M}$ and histamine at both 1 and $0.1 \mu \mathrm{M}$ (Fig. 3). In each of the three preparations tested, metiamide caused marked inhibition of the histamine-gastrin response. In earlier studies (3), this concentration of metiamide was found to abolish the response to $1 \mu \mathrm{M}$ histamine but had no effect on the small direct stimulation of oxygen uptake by $0.1 \mu \mathrm{M}$ gastrin. ${ }^{2} 10 \mu \mathrm{M}$ atropine did not inhibit the response to the histamine-gastrin combination (Fig. 3).

Histamine-carbamylcholine interactions. In nine consecutive preparations the addition of $1 \mathrm{mM}$ carbamylcholine resulted in a response that was $157.0 \pm 16.0 \%$ of the maximal response to histamine ( 10 $\mu \mathrm{M}$ ), with a range of 94.6 to $248.7 \%$ and the difference statistically significant by $t$ test for paired values $(P<0.01)$. The effects of several concentrations of carbamylcholine on the histamine dose-response relationship were studied (Fig. 4) as was the effect of a 10 $\mu \mathrm{M}$ histamine background on the dose-response relationship of carbamylcholine (data not shown). Enhancement was evident with histamine concentrations of 10 and $1 \mu \mathrm{M}$ and with carbamylcholine at concentrations above $1 \mu \mathrm{M}$.

There was considerable variability from preparation to preparation in the magnitude of the augmentary interactions between carbamylcholine and histamine as was observed with the interactions between histamine and gastrin. In three cell preparations (Figs. 4A and $4 \mathrm{C}$, for example) the magnitude of the interactions between $10 \mu \mathrm{M}$ histamine and $1 \mathrm{mM}$ carbamylcholine was great enough so that the response to the combination was greater than the sum of the individual responses. In each of five preparations where the interaction of carbamylcholine with a lower concentration of histamine $(1 \mu \mathrm{M})$ was tested, the response to the combination was greater than the sum of the individual responses ( $P=0.028$, by paired $t$ test).

As with the gastrin-histamine interactions, $0.1 \mathrm{mM}$ IMX was present for the study of these histaminecarbamylcholine interactions. In two preparations, histamine-carbamylcholine interactions were tested in the absence of IMX and significant enhancement was not demonstrated (data not shown).

The effects of atropine and metiamide on the carbamylcholine-histamine interaction. The effects of $10 \mu \mathrm{M}$ metiamide and $10 \mu \mathrm{M}$ atropine on the

\footnotetext{
${ }^{2}$ Because of the small magnitude of the gastrin response, the experiments in which metiamide was shown not to inhibit the direct response to gastrin (3) required serial determinations of the basal oxygen uptake and of the responses to gastrin and gastrin plus metiamide to achieve statistical significance. In Fig. 3B and C, the apparent return of the metiamide-treated histamine-gastrin combination to the base line raises the question of whether metiamide inhibits the direct response to gastrin. The experiments in Fig. 3 did not include an adequate number of properly sequenced determinations to answer this question.
} 

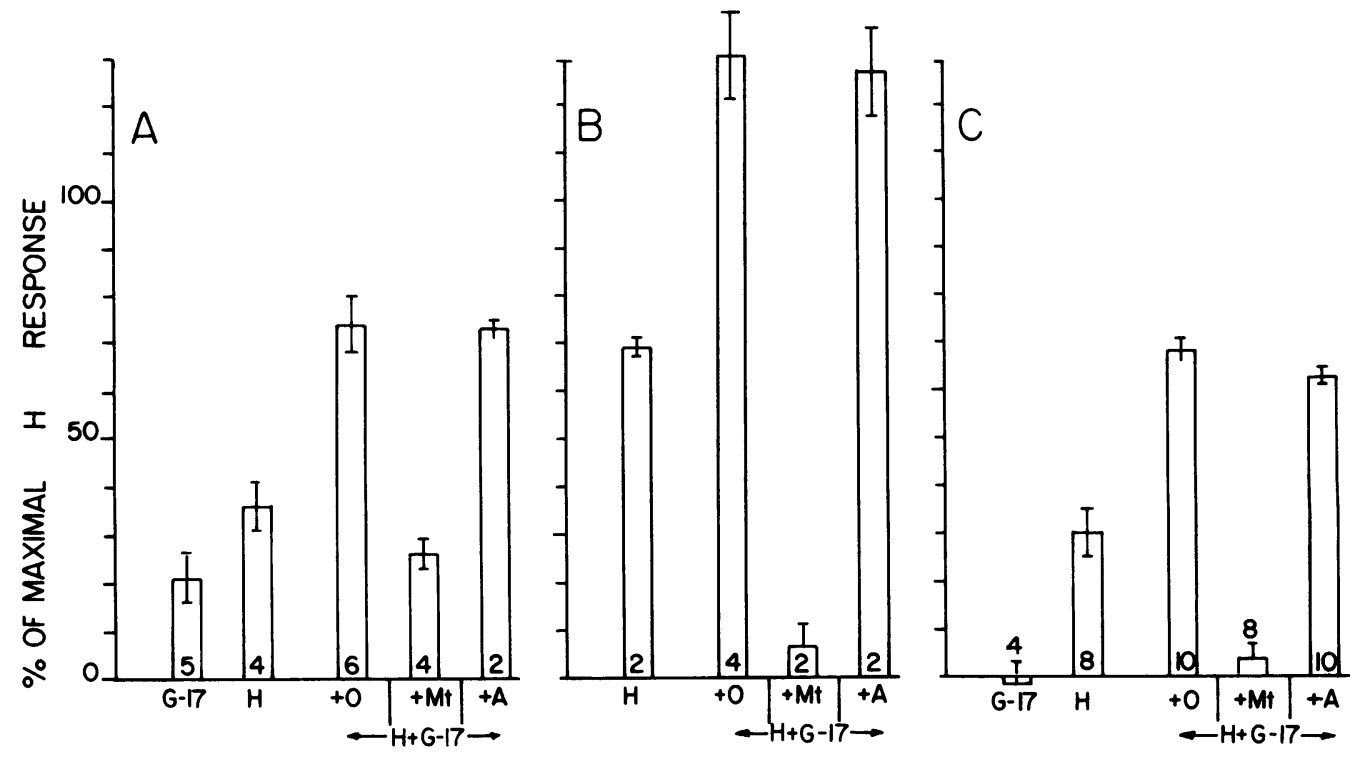

FIGURE 3 The effects of metiamide (Mt) and atropine (A) on the histamine-gastrin interaction. Oxygen uptake was determined for unenriched mucosal cells and expressed as the percentage of the maximal increment above basal produced by histamine $(\mathrm{H})(10 \mu \mathrm{M})$. Each panel represents a separate preparation, with the data representing the mean $\pm S E$ for the indicated number of determinations. The following concentration of agents were use: $0.1 \mu \mathrm{M}$ heptadecapeptide gastrin (G-17), $0.1 \mathrm{mM}$ IMX, $10 \mu \mathrm{M}$ metiamide, $10 \mu \mathrm{M}$ atropine, $0.1 \mu \mathrm{M}$ histamine in panels $\mathrm{A}$ and $\mathrm{C}$, and $1 \mu \mathrm{M}$ histamine in panel $\mathrm{B}$. The maximal responses produced by $10 \mu \mathrm{M}$ histamine were $98.6 \%$, $50.1 \%$ and $75.9 \%$ above basal in panels $\mathrm{A}, \mathrm{B}$, and $\mathrm{C}$, respectively. $0.1 \mathrm{mM}$ IMX was present in all incubations where histamine was used.

response to the combination of histamine and two concentrations of carbamylcholine were studied in three preparations (Fig. 5). Atropine partially inhibited the response to the combination of histamine and carbamylcholine, with the residual response similar to the response produced by histamine. The addition of metiamide to the histamine-carbamylcholine combination also caused partial inhibition with the remaining response similar to the response produced by carbamylcholine. The addition of both metiamide and atropine completely inhibited the histamine-carbamylcholine response.

Carbamylcholine-gastrin interactions. Interactions between carbamylcholine and gastrin were tested in five cell preparations. In the representative cell preparation in Table I as in four of the five preparations tested, the response to the combination of carbamylcholine and gastrin was greater than the responses to either agent alone. In all but one preparation however the response to the combination was less than the sum of the individual responses and also less than the maximal response to carbamylcholine alone. In two preparations carbamylcholine-gastrin interactions were also tested in the presence of IMX; in both instances the increment over IMX produced by the combination of carbamylcholine and gastrin was greater than the increment over IMX produced by either agent alone, but was less than the sum of these two latter increments (data for one experiment shown in Table I).

\section{DISCUSSION}

The emphasis of the present work has been to determine whether potentiating interactions between gastric secretagogues can be demonstrated with oxygen uptake as an index of the physiological response of isolated parietal cells. Any consideration of the interactions between secretagogues becomes immediately entangled in the confusion resulting from the contradictory definitions used to describe these interactions. Underlying this confusion is our lack of understanding of the mechanisms of these interactions. Emphasis has been placed in previous considerations of these interactions upon whether a combination of agents enhances the sensitivity (a decrease in the $D_{50}$, termed alternatively potentiation [15] and synergism [16]) or enhances the maximal response (termed alternatively effication [15] and potentiation [16]). Alternatively potentiating interactions have been said to exist when the response to the combination of agents exceeds the sum of the individual responses (17). These distinctions however do not have clear implications regarding the potential mechanisms of these interactions. The pres- 


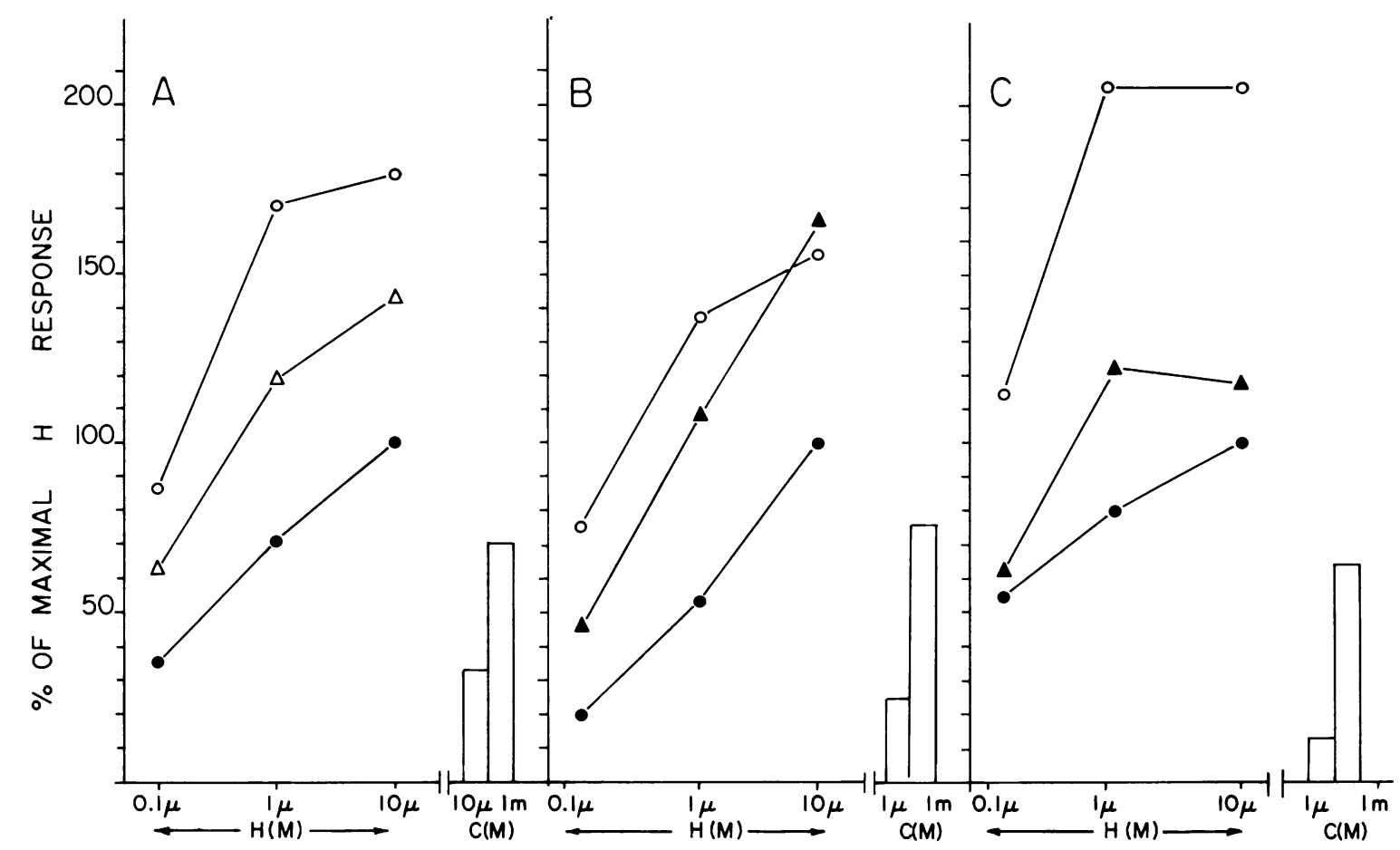

FIgure 4 The effects of carbamylcholine $(\mathrm{C})$ on the dose-response relationship to histamine $(\mathrm{H})$. Oxygen uptake was determined in three separate preparations and represents the mean of at least duplicate determinations in each preparation and has been expressed as the percentage of the maximal increment above basal produced by histamine $(10 \mu \mathrm{M})$. Histamine $(\Theta)$ was also tested with the following agents as background: $1 \mathrm{mM}$ carbamylcholine (O), $10 \mu \mathrm{M}$ carbamylcholine $(\triangle)$ and $1 \mu \mathrm{M}$ carbamylcholine $(\boldsymbol{\Delta})$. The responses to carbamylcholine alone are indicated by the open bars. The maximal responses to histamine $(10 \mu \mathrm{M})$ were $69.7 \%, 36.5 \%$, and $83.8 \%$ above basal in panels $\mathrm{A}, \mathrm{B}$, and $\mathrm{C}$, respectively. $0.1 \mathrm{mM}$ IMX was present when histamine was used.

ent work deals with the existence of potentiating interactions in isolated cells, not with the mechanisms involved, and for purposes of the present discussion interactions will be considered to be potentiating when the response to the combination of agents is either greater than the maximal response to either agent alone or greater than the sum of the individual responses.

In a previous study, histamine, gastrin, and cholinergic agents were found to stimulate oxygen uptake by isolated mammalian parietal cells (3). The isolated parietal cell appeared to have specific receptors for each of these three secretagogues in that anticholinergics and $\mathrm{H}_{2}$-receptor antagonists were specific for the actions of cholinergic agents and histamine respectively, and neither of these inhibitors altered the small direct response to gastrin (3). In the present study, interactions between histamine and cholinergic agents and between histamine and gastrin have been found. These interactions can be considered potentiating by either of the definitions mentioned above in that with both of these interactions the response to the combination of agents was greater than the maximal response to either agent alone and also greater than the sum of the individual responses. Furthermore, in this isolated parietal cell system, metiamide and atropine appeared to retain their respective specificities against the histaminic and cholinergic components of these interactions. It is important to note that under the in vitro conditions of the present study, gastrin alone was a weak stimulant of the isolated parietal cell, but that gastrin action was markedly enhanced by interaction with histamine. In a few cell preparations stimulation by gastrin alone was not apparent, whereas with a histamine background further stimulation by gastrin was of clear statistical significance (e.g., Fig. 3C).

These interactions between histamine and gastrin and histamine and carbamylcholine were demonstrated in the presence of IMX. Attempts to demonstrate these interactions without IMX did not achieve statistical significance. In previous studies of oxygen consumption (3), aminopyrine accumuluation (18), and cyclic AMP production (19), parietal cells prepared by the present techniques responded poorly to histamine in the absence of IMX. Phosphodiesterase inhibition by IMX however markedly potentiated the action of histamine on these three indices of response. This IMX 

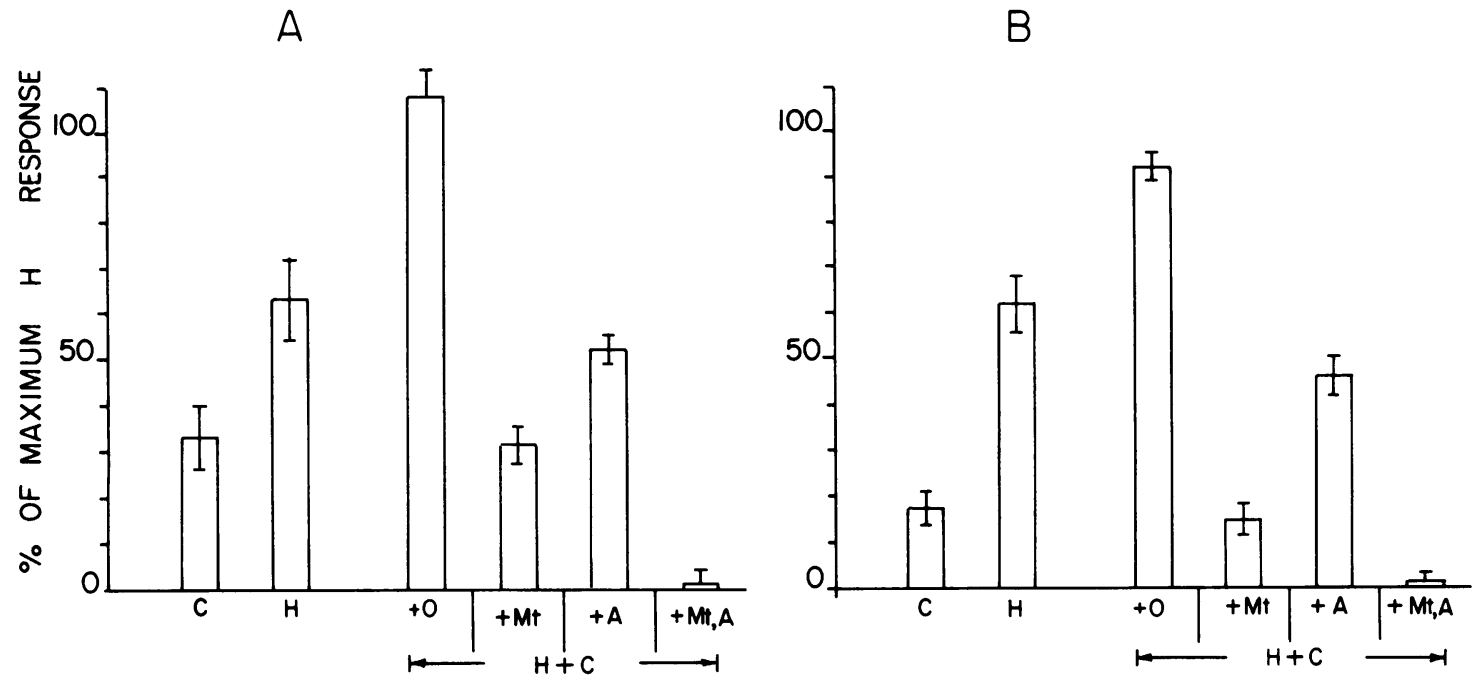

FIGURE 5 The effects of metiamide (Mt) and atropine (A) on the histamine-carbamylcholine interaction. Oxygen uptake is expressed as the percentage of the maximal response above basal produced by histamine $(\mathrm{H})(10 \mu \mathrm{M})$. (A) The data represent the mean $\pm \mathrm{SE}$ based upon four determinations from a single preparation of cells. The agents were studied at the following concentrations: $10 \mu \mathrm{M}$ carbamylcholine (C), $1 \mu \mathrm{M}$ histamine, $10 \mu \mathrm{M}$ metiamide, and $10 \mu \mathrm{M}$ atropine. (B) The data represent the mean \pm SE based upon six determinations pooled from two separate preparations of cells with the same agents as in A except for the use of $1 \mu \mathrm{M}$ carbamylcholine. The response to $10 \mu \mathrm{M}$ histamine was $73.3 \%$ above basal in $A$ and 89.8 and $92.5 \%$ above basal in the two experiments in B. $0.1 \mathrm{mM}$ IMX was present in all incubations where histamine was studied.

enhancement of cyclic AMP accumulation together with the IMX potentiation of oxygen uptake and aminopyrine accumulation suggests that these latter two effects of histamine are cyclic AMP dependent. In the present studies, phosphodiesterase inhibition also enhanced interactions between histamine and the other secretagogues thus supporting the view that cyclic AMP accumulation may be necessary for interactions with histamine to occur.

TABLE I

Interactions between Gastrin and Carbamylcholine

\begin{tabular}{lcc}
\hline & Increase in $\mathrm{O}_{2}$ uptake* & $n$ \\
\hline & $\%$ & \\
C $¥$ & $19.5 \pm 1.4$ & 4 \\
G-17 & $17.8 \pm 1.7$ & 4 \\
C + G-17 & $24.6 \pm 1.3$ & 4 \\
IMX & $24.1 \pm 1.3$ & 6 \\
IMX + C & $52.4 \pm 1.6$ & 6 \\
IMX + G-17 & $48.6 \pm 3.5$ & 4 \\
IMX + G-17 + C & $60.7 \pm 1.8$ & 6 \\
\hline
\end{tabular}

C, carbamylcholine; G-17, heptadecapeptide gastrin.

* Percentage increase in oxygen uptake over basal as the mean $\pm \mathrm{SE}$ for $n$ determinations from a single preparation of unenriched cells.

$\ddagger$ Agents used in the following concentrations: $1 \mu \mathrm{M} \mathrm{C}, 0.1$ $\mu \mathrm{M} \mathrm{G}-17$, and $0.1 \mathrm{mM}$ IMX.
Two observations indicate that histamine accounts for the major effects of interactions involving histamine and IMX, with IMX serving to potentiate the actions of histamine. Metiamide at $10 \mu \mathrm{M}$ appeared to be specific for histamine in that gastrin and carbamylcholine were not inhibited (3); however, stimulation by IMX alone was inhibited by metiamide (3). Furthermore, in light of this apparent specificity of metiamide, the observations that the response to the histamine-IMX-gastrin combination in the presence of metiamide was not greater than the response to gastrin alone and that the response to the histamine-IMX-carbamylcholine combination in the presence of metiamide was not greater than the response to carbamylcholine alone indicate that histamine accounts for the major effects of interactions involving histamine plus IMX.

In contrast to the potentiating interactions demonstrated between histamine and gastrin and histamine and carbamylcholine, interactions between gastrin and carbamylcholine were of much smaller magnitude and not clearly potentiating. Furthermore the presence of phosphodiesterase inhibition by IMX did not alter these findings with carbamylcholine and gastrin. It is clear however that in vivo potentiating interaction between cholinergic agents and gastrin do occur and in vivo atropine inhibits the action of gastrin (vide infra). Several possible factors may explain the present failure to clearly demonstrate potentiating gastrin-cholinergic 
interactions: (a) The present system of determining oxygen uptake may be too insensitive to demonstrate these interactions that may be present but of smaller magnitude than interactions involving histamine. (b) The absence of cholinergic-gastrin interactions may result from damage to the parietal cells during isolation. (c) These interactions may, in fact, be three-way interactions requiring the presence of histamine for their demonstration, a possibility that has not yet been tested. The study of cholinergic-gastrin interactions in vivo in the presence of $\mathrm{H}_{2}$-receptor blockade might throw light on whether this hypothesis has validity in vivo. (d) Gastrin-cholinergic interactions, although they occur in vivo, may not occur at the parietal cell itself. Other pathways may need to be intact for demonstration of these interactions.

The observation that the responses to the combinations of histamine and gastrin and histamine and carbamylcholine were greater than the maximal response to histamine plus IMX alone indicates that histamine cannot mediate all of the actions of gastrin and cholinergic agents on the parietal cell. It appears rather that the actions of gastrin and cholinergic agents must include a component of direct action on the parietal cell enhanced by interaction with the direct action of histamine on the parietal cell. The present results by no means exclude the possibility that gastrin and acetylcholine may also affect the metabolism of histamine by altering histamine uptake, the activity of histidine decarboxylase, or the release of histamine from mucosal stores.

Interaction between carbamylcholine and histamine has also been demonstrated in in vitro studies with gastric glands isolated from rabbit fundic mucosa (20). Berglindh did not, however, find either a direct response to gastrin or gastrin potentiation of histamine action, findings which were interpreted as indicating that gastrin does not act directly on the parietal cell. Failure to find gastrin action or interaction could however reflect selective impairment of the gastrin response resulting from use of a different enzyme (Collagenase I, $1 \mathrm{mg} / \mathrm{ml}$, Sigma Chemical Co., St. Louis, Mo.) or possibly from species differences.

That interactions occur in vivo between histamine, gastrin, and acetylcholine is suggested by several experimental findings. The actions of each of these three agents are enhanced by their simultaneous administration with a second secretagogue (16, 21-25); however, interactions demonstrated in this manner are species dependent and variable in magnitude (15, 26-28). A dramatic demonstration of secretagogue interactions has been made in studies with the ex vivo canine stomach preparation where marked potentiation was found between histamine and pentagastrin, between histamine and bethanechol, and between pentagastrin and bethanechol $(29,30)$. Further in vivo evidence for interactions between secretagogues comes from studies of secretagogue effect on acid secretion after both vagotomy and antrectomy. Vagotomy depresses acid secretion not only in response to vagal stimulation, but also in response to gastrin-, histamine-, and meal-stimulation (31-33). Furthermore, antrectomy removes not only the acid secretion stimulated by release of antral gastrin, but also decreases the direct secretory response to other stimuli $(34,35)$. Further indirect evidence that these interactions occur in vivo is provided by the observations that anticholinergics and $\mathrm{H}_{2}$-receptor antagonists block the actions of secretagogues other than only acetylcholine and histamine respectively, as was discussed earlier.

If one assumes that the differences between the in vitro and in vivo responses to inhibitors are attributable to the absence of endogenous secretagogues in the in vitro condition, one can construct a model (Fig. 6) that accounts for several of the in vivo observations cited above. With the isolated parietal cell system, by adding single agents one can demonstrate the direct and specific actions of secretagogues (dashed lines, Fig. 6), or by adding combinations of agents one can demonstrate the interactions between secretagogues (solid lines, Fig. 6). In this isolated cell system, anticholinergics and $\mathrm{H}_{2}$-antagonists are specific in their inhibition of both the direct actions and of the interactions involving cholinergic agents and histamine, respectively. However, it is just these specific effects which may account for the apparent lack of specificity of anticholinergics and $\mathrm{H}_{2}$-antagonists in vivo. $\mathrm{F}$ or example, when gastrin

\section{A WORKING HYPOTHESIS}

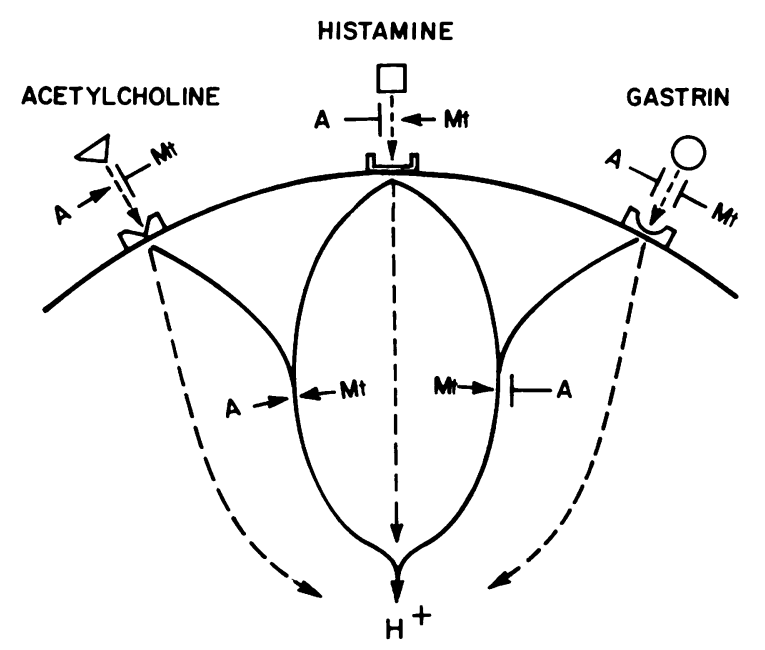

FIGURE 6 A working model for the actions and interactions of secretagogues on the isolated parietal cell. The dashed lines represent independent actions of secretagogues, and the solid lines represent interactions. Sites at which atropine (A) and metiamide $(\mathrm{Mt})$ are respectively inhibitory $(\rightarrow)$ and at which these agents are not inhibitory $(-\mid)$ are indicated. 
stimulation of the isolated parietal cell is enhanced by a threshold effect of histamine, then metiamide causes a dramatic apparent inhibition of this gastrin stimulation, an effect in the isolated cell system clearly due to inhibition of the histamine enhancement of gastrin action on the parietal cell.

The apparently conflicting in vivo observations can then be reconciled with the in vitro findings if one assumes the parietal cell in vivo is exposed to tonic and possibly phasic stimulation from locally secreted histamine and acetylcholine and from circulating gastrin. In light of this hypothesis, the in vivo action of any single exogenous stimulant of acid secretion would then in fact represent an interaction with the effects of these endogenous secretagogues on the parietal cell. Therefore, in vivo, in the absence of a means for eliminating endogenous secretagogues, one is limited to observing the interactions that occur between secretagogues (solid lines, Fig. 6). Consequently, the apparent lack of in vivo specificity of anticholinergic agents and $\mathrm{H}_{2}$-antagonists may result from their specifically inhibiting the respective endogenous cholinergic and histaminic enhancement of the action of other gastric stimulants rather than from interfering with the sequential mediation by acetylcholine or histamine of other secretagogue action or from directly interfering with the receptor binding of structurally unrelated secretagogues.

The interactions that occur between the three major stimulants of acid secretion are central to an understanding of the efficacy of several of the medical and surgical interventions used to treat peptic ulcer disease. The effectiveness of vagotomy and of antrectomy in duodenal ulcer disease results not only from the decrease in the direct stimulation of acid by vagal pathways and by gastrin, respectively, but also probably results from the respective removal of the cholinergic and gastrin components from the interactions that occur between secretagogues. $\mathrm{H}_{2}$-receptor antagonists have been remarkably effective agents in decreasing acid secretion in duodenal ulcer patients $(36,37)$ and in patients with the Zollinger-Ellison syndrome (38). This effectiveness of $\mathrm{H}_{2}$-blockers has been taken as evidence that other secretagogues may act by releasing histamine; the present data are not compatible with such a model as the only mechanism for secretagogue interaction. These results are compatible with a model in which histamine is spontaneously released in vivo and markedly augments the action of other secretagogues; $\mathrm{H}_{2}$-receptor antagonists block these interactions.

\section{ACKNOWLEDGMENTS}

The author is deeply indebted to Dr. Morton I. Grossman for the invaluable support and direction that he has offered at every stage of this work and to Aija Fox and Raymond L. Melendez for their indispensable contributions to the de- velopment and application of these techniques. The author is also indebted to Doctors John Walsh, Armin Wollin, Travis Solomon, and Charles Code for their many helpful discussions and contributions, to Dr. Janet Elashoff for her advice regarding the statistical analyses, and to Mrs. Ruth Abercrombie for her excellent secretarial assistance.

This project was supported, in part, by the Center for Ulcer Research and Education (grant AM 17328) and grant AM 19984, both from the National Institute of Arthritis, Metabolism, and Digestive Diseases.

\section{REFERENCES}

1. Soll, A. H. 1976. The isolated mammalian parietal cell: Actions and interactions of secretagogues. Gastroenterology. 70: 794 .

2. Soll, A. H. 1976. Isolated mammalian parietal cells: Effects of atropine (A) and metiamide (M) on the actions and interactions of secretagogues. Gastroenterology. 72: 824.

3. Soll, A. H. 1978. The actions of secretagogues on oxygen uptake by isolated mammalian parietal cells. J. Clin. Invest. 61: 370-380.

4. Code, C. F., N. C. Hightower, and G. A. Hallenbeck. 1951. Comparison of the effects of methantheline bromide (Banthine) and atropine on the secretory responses of vagally innervated and vagally denervated gastric pouches. Gastroenterology. 19: 254-264.

5. Konturek, S. J., J. Oleksy, and A. Wysocki. 1968. Effect of atropine on gastric acid response to graded doses of pentagastrin and histamine in duodenal ulcer patients before and after vagotomy. Am. J. Dig. Dis. 13: 792-800.

6. Hirschowitz, B. I., and G. Sachs. 1969. Atropine inhibition of insulin, histamine, and pentagastrin stimulated gastric electrolyte and pepsin secretion in the dog. Gastroenterology. 56: 693-702.

7. Hirschowitz, B. I., and G. A. Hutchison. 1977. Kinetics of atropine inhibition of pentagastrin-stimulated $\mathrm{H}^{+}$, electrolyte, and pepsin secretion in the dog. Am. J. Dig. Dis. 22: 99-107.

8. Black, J. W., W. A. M. Duncan, C. J. Durant, C. R. Ganellin, and E. M. Parsons. 1972. Definition and antagonism of histamine $\mathrm{H}_{2}$ receptors. Nature (Lond.). 236: 385-390.

9. Thjodleifsson, B., and K. G. Wormsley. 1975. Aspects of the effect of metiamide on pentagastrin-stimulated and basal gastrin secretion of acid and pepsin in man. Gut. 16: $50 \mathrm{i}-508$.

10. Aadland, E., A. Berstad, and L. S. Semb. 1977. Inhibition of pentagastrin-stimulated gastric secretion by cimetidine in healthy subjects. In Cimetidine, Proceedings of the Second International Symposium on Histamine $\mathrm{H}_{2}$ Receptor Antagonists. W. L. Burland and M. A. Simkins, editors. Excerpta Medica, Amsterdam-Oxford. 87-97.

11. Grossman, M. I., and S. J. Konturek. 1974. Inhibition of acid secretion in dog by metiamide, a histamine antagonist acting on $\mathrm{H}_{2}$ receptors. Gastroenterology. 66: 517-521.

12. Gibson, R., B. I. Hirschowitz, and G. Hutchison. 1974 Actions of metiamide, and $\mathrm{H}_{2}$-histamine receptor antagonist, on gastric $\mathrm{H}^{+}$and pepsin secretion in dogs. Gastroenterology. 67: 93-99.

13. Carter, D. C., J. A. H. Forrest, M. Werner, R. C. Heading, J. Park, and D. J. C. Shearman. 1974. Effect of histamine $\mathrm{H}_{2}$-receptor blockade on vagally induced gastric secretion in man. Br. Med. J. 3: 554-556.

14. Schoon, I., and L. Olbe. 1977. Effect of cimetidine on cholinergic reflex stimulation of gastric acid secretion in duodenal ulcer patients. In Cimetidine, Proceedings of the Second International Symposium on Histamine 
$\mathrm{H}_{2}$-Receptor Antagonists. W. L. Burland and M. A. Simkins, editors. Excerpta Medica, Amsterdam-Oxford. $207-213$.

15. Grossman, M. I. 1974. Potentiation of pentagastrin by carbachol in cat. Gastroenterology. 67: 1081.

16. Hirschowitz, B. I., and G. A. Hutchison. 1975. Effect of vagotomy on urecholine modified histamine dose responses in dog. Am. J. Physiol. 228: 1313-1318.

17. Gardner, J. D., M. J. Jackson, S. Batzri, and R. T. Jensen. 1978. Potential mechanisms of interactions among secretagogues. Gastroenterology. 74: In press.

18. Soll, A. H. 1977. Secretagogue stimulation of $\mathrm{O}_{2}$ consumption and ${ }^{14} \mathrm{C}$-aminopyrine uptake by enriched canine parietal cells. Gastroenterology. 72: 1166.

19. Soll, A. H., and A. Wollin. 1977. The effects of histamine, prostaglandin $\mathrm{E}_{2}$, and secretin on cyclic AMP in separated canine fundic mucosal cells. Gastroenterology. 72: 1166.

20. Berglindh, T. 1977. Potentiation by carbachol and aminophylline of histamine- and db-cAMP-induced parietal cell activity in isolated gastric glands. Acta Physiol. Scand. 99: 75-84.

21. Gillespie, I. E., and M. I. Grossman. 1964. Potentiation between urecholine and gastrin extract and between urecholine and histamine in stimulation of Heidenhain pouches. Gut. 5: 71-76.

22. Grossman, M. I. 1967. Neural and hormonal stimulation of gastric secretion of acid. Handb. Physiol. 2 (Sect. 6): 835-863.

23. Johnson, L. R., and M. I. Grossman. 1969. Potentiation of gastric acid response in the dog. Gastroenterology. 56: 687-692.

24. Konturek, S. J., and J. Oleksy. 1967. Potentiation between pentapeptide (ICI 50, 123) and histamine in stimulation of gastric secretion in man. Gastroenterology. 53: 912-917.

25. Cooke, A. R. 1970. Potentiation of acid output in man by a distention stimulus. Gastroenterology. 58: 633-637.

26. Brooks, A. M., L. R. Johnson, and M. I. Grossman. 1970. Effects of combinations of histamine and pentagastrin on gastric secretion in man and dog. Gastroenterology. 58: 470-475.

27. Dinbar, A., and M. I. Grossman. 1972. Interaction of stimulants of acid secretion in cat. Gastroenterology. 62: $242-246$.

28. Hirschowitz, B. I., G. Sachs, and G. Hutchison. 1973.
Lack of potentiation or synergism between histamine and pentagastrin in the fistula dog. Am. J. Physiol. 224: 509-513.

29. Kowalewski, K. and M. Saab. 1972. Potentiation between pentagastrin and bethanechol chloride in stimulation of gastric secretion from isolated ex vivo canine stomach perfused with homologous blood. Pharmacology (Basel). 7: 225-236.

30. Kowalewski, K., and A. Kolodej. 1972. Potentiation between pentagastrin and histamine in stimulation of secretion from totally isolated ex vivo canine stomach. Pharmacology (Basel). 7: 357-365.

31. Emås, S., and M. I. Grossman. 1967. Effect of truncal vagotomy on acid and pepsin responses to histamine and gastrin in dogs. Am. J. Physiol. 212: 1007-1012.

32. Hirschowitz, B. I., and G. A. Hutchison. 1977. Long term effects of highly selective vagotomy (HSV) in dogs on acid and pepsin secretion. Am. J. Dig. Dis. 22: 81-95.

33. Konturek, S. J., A. Wysocki, and J. Oleksy. 1968. Effect of medical and surgical vagotomy on gastric response to graded doses of pentagastrin and histamine. Gastroenterology. 54: 392-400.

34. Olbe, L. 1964. Effect of resection of gastrin releasing regions on acid response to sham feeding and insulin hypoglycemia in Pavlov pouch dogs. Acta Physiol. Scand. 62: $169-175$.

35. Bergegardh, S., G. Broman, U. Knutson, L. Palmer, and L. Olbe. 1976. Gastric acid responses to graded i.v. infusions of pentagastrin and histalog in peptic ulcer patients before and after antrum-bulb resection. Scand. J. Gastroenterol. 11: $337-346$.

36. Richardson, C. T., B. A. Bailey, J. H. Walsh, and J. S. Fordtran. 1975. The effect of an $\mathrm{H}_{2}$-receptor antagonist on food-stimulated acid secretion, serum gastrin, and gastric emptying in patients with duodenal ulcer.J. Clin. Invest. 55: $536-542$.

37. Burland, W. L. and M. A. Simkins, editors. 1977. Cimetidine, Proceedings of the Second International Symposium on Histamine $\mathrm{H}_{2}$-Receptor Antagonists. Excerpta Medica, Amsterdam-Oxford. 217-281.

38. Richardson, C. T., and J. H. Walsh. 1976. The value of a histamine $\mathrm{H}_{2}$-receptor antagonist in the management of patients with the Zollinger-Ellison syndrome. N. Engl.J. Med. 294: 133-135. 